This document is the accepted manuscript version of the following article:

Mandal, S., Song, G., Rossi, R. M., \& Grover, I. B. (2021). Characterization and modeling of thermal protective fabrics under Molotov cocktail exposure. Journal of Industrial Textiles. https://doi.org/10.1177/1528083720984973

\title{
Characterization and modeling of thermal protective fabrics under Molotov cocktail exposure
}

\author{
Sumit Mandal ${ }^{1}$, Guowen Song ${ }^{2}$, Rene M. Rossi ${ }^{3}$, Indu Bala Grover ${ }^{4}$
}

${ }^{1}$ Departmen of Design, Housing, and Merchandising, Oklahoma State University, Stillwater, USA

${ }^{2}$ Department of Apparel, Events, and Hospitality Management, Iowa State University, Ames, USA

${ }^{3}$ Empa, Swiss Federal Laboratories for Materials Science and Technology, St. Gallen, Switzerland

${ }^{4}$ Department of Computer Engineering, YMCA Institute of Engineering, Faridabad, India

Corresponding Author: Dr. Sumit Mandal (sumit.mandal@okstate.edu), Oklahoma State University, USA

\begin{abstract}
This study aims to characterize and model the thermal protective fabrics usually used in workwear under Molotov cocktail exposure. Physical properties of the fabrics were measured; and, thermal protective performances of the fabrics were evaluated under a fire exposure generated from the laboratory-simulated Molotov cocktail. The performance was calculated in terms of the amount of thermal energy transmitted through the fabrics; additionally, the time required to generate a second-degree burn on wearers' bodies was predicted from the calculated transmitted thermal energy. For the characterization, the parameters that affected the protective performance were identified and discussed with regards to the theory of heat and mass transfer. The relationships between the properties of the fabric systems and the protective performances were statistically analyzed. The significant fabric properties affecting the performance were further employed in the empirical modeling techniques - Multiple Linear Regression (MLR) and Artificial Neural Network (ANN) for predicting the protective performance. The Coefficient of Determination $\left(\mathrm{R}^{2}\right)$ and Root Mean Square Error (RMSE) of the developed MLR and ANN models were also compared to identify the best-fit model for predicting the protective performance. This study found that thermal resistance and evaporative resistance are two significant properties $(\mathrm{P}-$ Values $<0.05)$ that negatively affect the transmitted thermal energy through the fabric systems. Also, $\mathrm{R}^{2}$ and RMSE values of ANN model were much higher $\left(\mathrm{R}^{2}=0.94\right)$ and lower $(\mathrm{RMSE}=37.42)$, respectively, than MLR model $\left(\mathrm{R}^{2}\right.$ $=0.73$; RMSE $=191.38$ ); therefore, ANN is the best-fit model to predict the protective performance. In summary, this study could build an in-depth understanding of the parameters that can affect the protective performance of fabrics used in the workwear of high-risk sectors employees and would provide them better occupational health and safety.
\end{abstract}

Keywords: Molotov cocktail, protective fabrics, workwear, fabric properties, protective performance, modeling

\section{Introduction}

During last few decades, the occurrences of fire exposures to the employees of different high-risk sectors (e.g., firefighting, defense, secret services and police) have increased hugely and it may put them at risk of getting significant burn injuries on their bodies [1-3]. In this situation, the workwear used by these employees becomes very important to get protec- 
tion from burn injuries $[4,5]$. Nevertheless, the thermal protective performance of their workwear mainly depends upon the characteristics of fabrics materials used in the workwear and types of exposed fires [6-9]. In these fabrics, namely petroleum based inherently fireretardant fibers (e.g., meta-aramid, para-aramid) are used; however, the recent advancements have also functionalized the natural cellulosic fibers to be used in these fabrics $[10,11]$.

Considering the above situation, different organizations [e.g., International Organization for Standardization (ISO), American Society for Testing and Materials (ASTM), Comité Européen de Normalisation (CEN)] have developed the standard methods (e.g., ISO 9151, ISO 6942, ASTM F 2700, ASTM F 1060, ASTM F 2703) for evaluating the thermal protective performance of fabrics used in the workwear under different types of fire exposures [1218]. These standards are mainly used for evaluating the protective performance of fabrics under the flame (simulated by fueling a flammable gas), radiant-heat (simulated by heating a coil), or hot surface contact (simulated by heating a solid metal plate that is placed on an electrically operated hot-plate) exposures $[6,13,19]$. By using or customizing these standards, many researchers have also evaluated and characterized the thermal protective performance of fabrics [13, 20-22]. Based on their research, they identified and discussed various parameters (e.g., fabric properties, test configurations) that could significantly affect the protective performance of fabrics. By employing these parameters, previous researchers have also developed the empirical models for predicting the performance [20, 23, 24]. It has been found that empirical Artificial Neural Network (ANN) model could perform significantly better than the Multiple Linear Regression (MLR) model in order to predict the performance.

Although previous researchers $[2,7,9,20-24]$ extensively studied the thermal protective performance of fabrics under various fire exposures (flame, radiant-heat, and/or hot surface contact), it is notable that the high-risk sectors employees (e.g., police, military, firefighters, secret service agents) are not limited to expose to only these types of fires. In the case of civic unrest or riots, it has been commonly observed that the high-risk sectors' employees 
need to control or face the protestors or rioters. In such critical situations, it is most likely that they might be exposed to Molotov cocktails (i.e., flammable liquids-based firebombs) hurled by the protestors or rioters. For example, in a most recent incident on May 31, 2020 in Washington, USA, at least 50 secret service agents got exposed to Molotov cocktail attacks during the protest of 'Black Lives Matter' [25, 26]. Sometimes, an exposure to Molotov cocktail may cause serious burn injuries to high-risk sectors employees. Considering this, Kemp et al. (2016) recently developed an instrument that could be used to evaluate the thermal protective performance of fabrics under the Molotov cocktail exposure [27]. This study extensively investigated various aspects related to the test apparatus/methods (e.g., angle of hurling the flammable liquids, volume of flammable liquids) and their effect on the thermal protective performance of fabrics. However, this study did not properly characterize the thermal protective performance of fabrics in order to analyze various fabric properties and structures that could impact the protective performance. As a result, the knowledge of thermal protective performance of fabrics under the Molotov cocktail exposure is still limited and fragmented.

In this study, the thermal protective performance of fabrics used in the workwear was evaluated under a Molotov cocktail exposure. The parameters (fabric properties and structures, test configuration) that affected the protective performance were identified and discussed with regard to the scientific theory of heat and mass transfer. The relationship between the fabrics' properties and their protective performances were statistically analyzed. The identified significant fabric properties were further employed in the empirical modeling techniques for predicting the protective performance. This study could help the textile and materials engineers to develop a thorough understanding on the thermal protective performance of fabrics under the Molotov cocktail exposure. This enhanced understanding could lead towards developing a new fabric in order to provide better occupational protection to the high-risk sectors' employees. 


\section{Fabric selection and properties evaluation}

In the manufactured workwear for high-risk sectors' employees, layered fabric systems are generally used. These fabric systems consist of different types of high-performance fabrics (an outer shell, a moisture barrier, and/or a thermal liner) in an assembly [28-30]. In this study, the commercially available and commonly used high-performance fabrics in the manufacturing of thermal protective clothing were selected based on the fiber content, weave structure, mass, thickness, and air permeability (Table 1). These fabrics were purchased from the North American textile industries. Next, these fabrics were assembled in different combinations to prepare the layered fabric systems (single-, double-, and triple-layered) to fulfil the objectives of this study (Table 2). A pictorial representation of the layers in a particular combination (e.g., AED in Table 2) used in the fabric has been shown in Figure 1. Notably, the number of prepared fabric systems or the sample size for this study was relatively small; however, the small sample size is common to most textile experimental research and this does not adversely affect the data analysis $[31,32]$. In these fabric systems, the outer layer (OL) faces the thermal exposure, the inner layer (IL) remains closest to the skin simulant sensor or the wearers' skin, and the middle layer (ML) sandwiches between OL and IL.

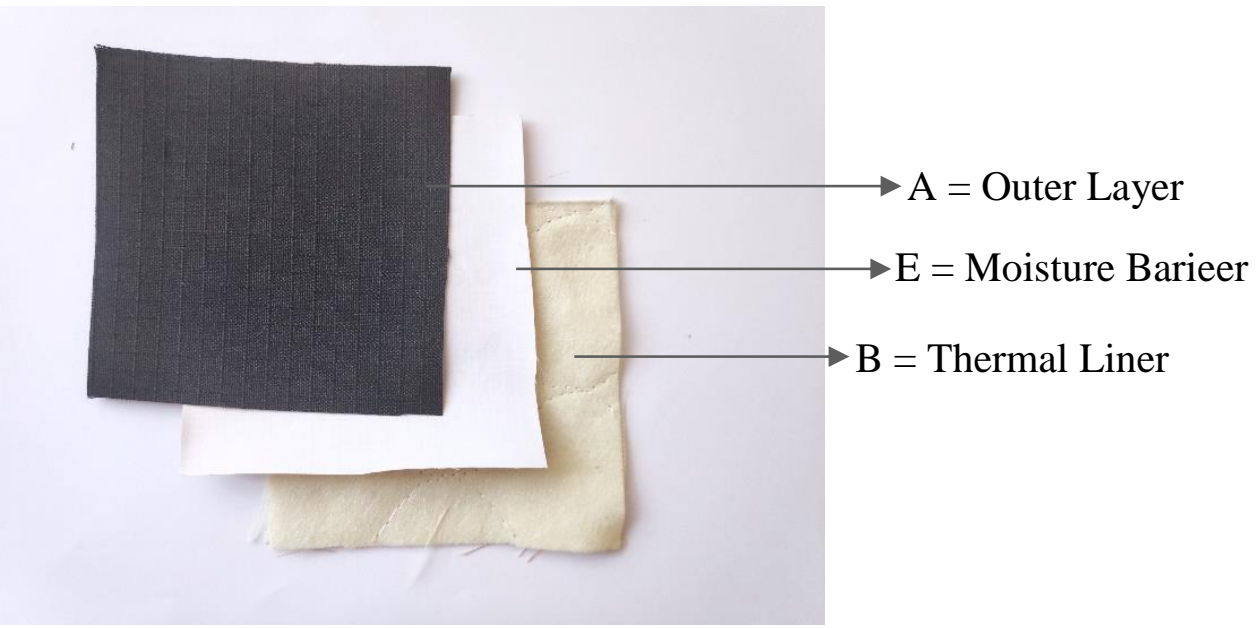

Figure 1: Pictorial representation of the technical face side of AED fabric system in Table 2. 
The physical properties (thickness, air permeability, thermal resistance, and evaporative resistance) of each of these fabrics or fabric systems were measured according to ASTM standards and their mean value was calculated by maintaining a Coefficient of Variation (CV) between $1-2.5 \%$. These mean values are presented in Table 1 and Table 2. For the statistical data analysis, the measured physical properties (thickness, air permeability, thermal resistance, and evaporative resistance) were considered as independent variables with respect to the dependent variable (thermal protective performance). Here, the number of physical properties considered were limited to four because the sample size of this study is relatively small. Generally, fewer independent variables are recommended for statistical analysis, especially where the sample size is small [32]. 
Table 1. Constructional features of fabrics used in this work

\begin{tabular}{|c|c|c|c|c|c|}
\hline Fabric types & Fiber content & Weave structure & $\begin{array}{l}\operatorname{Mass}^{\mathrm{a}} \\
\left(\mathrm{g} / \mathbf{m}^{2}\right)\end{array}$ & $\begin{array}{l}\text { Thickness }^{\mathrm{b}} \\
\text { (mm) }\end{array}$ & $\begin{array}{c}\text { Air } \\
\text { permeability }^{\mathrm{c}} \\
\left(\mathrm{cm}^{3} / \mathrm{cm}^{2} / \mathrm{s}\right) \\
\end{array}$ \\
\hline A (Outer Shell) & $\begin{array}{l}60 \% \text { Kevlar }^{\circledR} \text { aramid and } \\
40 \% \text { Polybenzimidazole }\end{array}$ & Plain weave, rip-stop woven & $\begin{array}{c}248 \\
(0.003 \%)\end{array}$ & $\begin{array}{c}0.69 \\
(2.45 \%)\end{array}$ & $\begin{array}{l}15.7 \\
(2.40 \%)\end{array}$ \\
\hline B (Thermal liner) & $100 \%$ Nomex $^{\circledR}$ aramid & $\begin{array}{l}\text { Plain weave Nomex }{ }^{\circledR} \text { layer } \\
\text { quilted to two thin Nomex }{ }^{\circledR} \\
\text { oriented webs }\end{array}$ & $\begin{array}{c}209 \\
(0.002 \%)\end{array}$ & $\begin{array}{l}1.63 \\
(1.40 \%)\end{array}$ & $\begin{array}{l}43.2 \\
(2.50 \%)\end{array}$ \\
\hline $\mathrm{C}$ (Thermal liner) & $100 \%$ Nomex $^{\circledR}$ aramid & $\begin{array}{l}\text { Plain weave Nomex }{ }^{\circledR} \text { layer } \\
\text { quilted to Nomex }{ }^{\circledR} \text { needle- } \\
\text { felted batt }\end{array}$ & $\begin{array}{c}289 \\
(0.003 \%)\end{array}$ & $\begin{array}{l}2.13 \\
(2.48 \%)\end{array}$ & $\begin{array}{l}40.6 \\
(2.31 \%)\end{array}$ \\
\hline D (Thermal liner) & $100 \%$ Nomex $^{\circledR}$ aramid & $\begin{array}{l}\text { Plain weave Nomex }{ }^{\circledR} \text { layer } \\
\text { quilted to a Nomex }{ }^{\circledR} \text { scrim, } \\
\text { needle-felted batt, and scrim }\end{array}$ & $\begin{array}{c}351 \\
(0.004 \%)\end{array}$ & $\begin{array}{l}3.18 \\
(2.29 \%)\end{array}$ & $\begin{array}{c}38.4 \\
(2.50 \%)\end{array}$ \\
\hline E (Moisture Barrier) & $\begin{array}{l}85 \% \text { Nomex-IIIA }^{\circledR} \text { and } \\
15 \% \text { polyurethane }\end{array}$ & $\begin{array}{l}\text { Plain weave Nomex }{ }^{\circledR} \text { back- } \\
\text { coated with polyurethane } \\
\text { film }\end{array}$ & $\begin{array}{l}211 \\
(0.005 \%)\end{array}$ & $\begin{array}{l}0.85 \\
(2.28 \%)\end{array}$ & $\begin{array}{c}0 \\
(\mathrm{NA})\end{array}$ \\
\hline
\end{tabular}

a Measured according to ASTM D 3776 [33].

${ }^{\mathrm{b}}$ Measured according to ASTM D 1777 under 1kPa pressure [34].

${ }^{\mathrm{c}}$ Measured according to ASTM D 737 under air pressure differential 125Pa [35]. 
Table 2. Structural configurations and physical properties of the fabric systems

\begin{tabular}{|c|c|c|c|c|c|c|}
\hline $\begin{array}{l}\text { Fabric } \\
\text { construction }\end{array}$ & $\begin{array}{c}\text { Fabric } \\
\text { systems }\end{array}$ & $\begin{array}{c}\text { Structural } \\
\text { configurations }\end{array}$ & $\begin{array}{l}\text { Thickness } \\
\text { (mm) }\end{array}$ & $\begin{array}{c}\text { Air } \\
\text { permeability } \\
\left(\mathrm{cm}^{3} / \mathrm{cm}^{2} / \mathrm{s}\right) \\
\end{array}$ & $\begin{array}{c}\text { Thermal } \\
\text { resistance }^{\mathrm{f}} \\
\left({ }^{\circ} \mathbf{K} \cdot \mathbf{m}^{2} / \mathbf{W}\right)\end{array}$ & $\begin{array}{c}\text { Evaporative } \\
\text { resistance } \\
\left(\mathrm{m}^{2} \cdot \mathrm{Pa} / \mathrm{W}\right)\end{array}$ \\
\hline $\begin{array}{l}\text { Single- } \\
\text { layered }\end{array}$ & A & Fabric A & $\begin{array}{l}0.69 \\
(2.45 \%)\end{array}$ & $\begin{array}{l}15.71 \\
(2.40 \%)\end{array}$ & $\begin{array}{l}0.073 \\
(1.28 \%)\end{array}$ & $\begin{array}{r}4.40 \\
(2.27 \%)\end{array}$ \\
\hline \multirow{4}{*}{$\begin{array}{l}\text { Double- } \\
\text { layered }\end{array}$} & $\mathrm{AB}$ & Fabric A (OL) + Fabric B ${ }^{\mathrm{a}}(\mathrm{IL})$ & $\begin{array}{c}2.18 \\
(2.26 \%)\end{array}$ & $\begin{array}{l}13.59 \\
(2.48 \%)\end{array}$ & $\begin{array}{l}0.117 \\
(1.30 \%)\end{array}$ & $\begin{array}{r}9.87 \\
(1.17 \%)\end{array}$ \\
\hline & $\mathrm{AD}$ & Fabric A (OL) + Fabric D ${ }^{\mathrm{b}}(\mathrm{IL})$ & $\begin{array}{c}3.53 \\
(2.09 \%)\end{array}$ & $\begin{array}{l}13.30 \\
(2.21 \%)\end{array}$ & $\begin{array}{l}0.169 \\
(1.36 \%)\end{array}$ & $\begin{array}{l}12.70 \\
(0.79 \%)\end{array}$ \\
\hline & $\mathrm{AE}$ & Fabric $A(O L)+$ Fabric $E^{d}(I L)$ & $\begin{array}{l}1.42 \\
(0.6 \%)\end{array}$ & $\begin{array}{c}0 \\
(\mathrm{NA})\end{array}$ & $\begin{array}{l}0.095 \\
(1.22 \%)\end{array}$ & $\begin{array}{l}20.70 \\
(0.84 \%)\end{array}$ \\
\hline & EA & Fabric $\mathrm{E}^{\mathrm{e}}(\mathrm{OL})+$ Fabric $\mathrm{A}(\mathrm{IL})$ & $\begin{array}{c}1.42 \\
(0.96 \%)\end{array}$ & $\begin{array}{c}0 \\
(\mathrm{NA})\end{array}$ & $\begin{array}{l}0.095 \\
(1.05 \%) \\
\end{array}$ & $\begin{array}{l}21.17 \\
(0.27 \%)\end{array}$ \\
\hline \multirow{4}{*}{$\begin{array}{l}\text { Triple- } \\
\text { layered }\end{array}$} & AEB & $\begin{array}{l}\text { Fabric } A(O L)+\text { Fabric } E^{d}(M L)+ \\
\text { Fabric } B^{\mathrm{a}}(\mathrm{IL})\end{array}$ & $\begin{array}{c}2.88 \\
(2.25 \%)\end{array}$ & $\begin{array}{c}0 \\
(\mathrm{NA})\end{array}$ & $\begin{array}{l}0.129 \\
(1.18 \%)\end{array}$ & $\begin{array}{l}25.90 \\
(0.39 \%)\end{array}$ \\
\hline & $\mathrm{AEC}$ & $\begin{array}{l}\text { Fabric } A(O L)+\text { Fabric } E^{d}(M L)+ \\
\text { Fabric } C^{c}(I L)\end{array}$ & $\begin{array}{c}3.49 \\
(2.48 \%) \\
\end{array}$ & $\begin{array}{c}0 \\
(\mathrm{NA})\end{array}$ & $\begin{array}{l}0.151 \\
(1.15 \%) \\
\end{array}$ & $\begin{array}{l}25.40 \\
(1.97 \%) \\
\end{array}$ \\
\hline & AED & $\begin{array}{l}\text { Fabric A (OL) + Fabric } \mathrm{E}^{\mathrm{d}}(\mathrm{ML})+\text { Fabric } \mathrm{D}^{\mathrm{b}} \\
\text { (IL) }\end{array}$ & $\begin{array}{l}4.23 \\
(2.04 \%)\end{array}$ & $\begin{array}{c}0 \\
0 \\
(\mathrm{NA})\end{array}$ & $\begin{array}{l}0.184 \\
(1.44 \%)\end{array}$ & $\begin{array}{l}28.03 \\
(2.15 \%)\end{array}$ \\
\hline & EAC & $\begin{array}{l}\text { Fabric } \mathrm{E}^{\mathrm{e}}(\mathrm{OL})+\text { Fabric } \mathrm{A}(\mathrm{ML})+\text { Fabric } \mathrm{C}^{\mathrm{c}} \\
(\mathrm{IL})\end{array}$ & $\begin{array}{c}3.49 \\
(2.50 \%)\end{array}$ & $\begin{array}{c}0 \\
(\mathrm{NA})\end{array}$ & $\begin{array}{l}0.151 \\
(1.38 \%)\end{array}$ & $\begin{array}{l}25.37 \\
(0.60 \%)\end{array}$ \\
\hline
\end{tabular}

aThe web side of Fabric B is in contact with wearers' skin.

'The scrim side of Fabric D is in contact to wearers' skin.

'The batt side of Fabric $\mathrm{C}$ is in contact with wearers' skin.

dThe polyurethane coated side of Fabric E faces Fabric A.

${ }^{\mathrm{e}}$ The polyurethane coated side of Fabric E faces a Molotov cocktail exposure.

${ }^{\mathrm{f}}$ Measured according to ASTM D 1518 [36].

gMeasured according to ISO 11092 [37]. 


\section{Test conditions and approaches}

The protective performances of three specimens $(340 \mathrm{~mm} \times 170 \mathrm{~mm})$ of each selected single-, double-, and triple-layered fabric system were evaluated under a Molotov cocktail exposure using a bench-scale test. Before testing, the specimens were conditioned at $20 \pm 2^{\circ} \mathrm{C}$ temperature and $65 \pm 5 \%$ relative humidity for at least 24 hours in accordance with ISO 139 [38]. Then, these specimens were subjected to a laboratory-simulated Molotov cocktail exposure tests conducted at Empa - Swiss Federal Laboratories for Materials Science, Switzerland.

During the Molotov cocktail exposure (Figure 2), a specimen of each fabric system was placed on a $30^{\circ}$ inclined sensor board in such a way that the outer layer of the specimen could be exposed to the Molotov cocktail fire. The sensor board had a size of $290 \mathrm{~mm} \times 180$ $\mathrm{mm}$ and it was made by a low thermal conductive $(0.18 \mathrm{~W} / \mathrm{m} . \mathrm{K})$, liquid- and heat-resistant material - more specifically, the water regain of the sensor board material was $0.2 \%$ (at $23^{\circ} \mathrm{C}$ for 24 hours) and the materials used in the sensor board can resist the heat up to $800^{\circ} \mathrm{C}$. While the top edge of the specimen was clamped on the upper edge of the sensor board; and a 500gm mass was attached to the lower edge of the specimen in order to provide the equal amount of tension on each tested fabric specimen. The sensor board was instrumented with 10 human skin simulating sensors (made by epoxy resin slab with encapsulated T-type thermocouple) developed by Precision Products, USA. A fuel reservoir was placed over the last sensor on the upper edge of the sensor board. Before starting the testing, $4 \mathrm{ml}$ of fuel was pipetted in the reservoir and ignited. The fuel was kept in ignited condition for 10 seconds, and then tipped onto the fabric specimen using a simple pulley system. During and after the fire exposure (a total of 100 seconds), the temperature rise of the sensors was recorded using a software. From this temperature rise, the amount of heat flux transmitted through the specimen was measured. In this study, the heat flux under a particular fire exposure was measured using Equation 1, where, $\mathrm{q}=$ heat flux $\left(\mathrm{cal} / \mathrm{sec} / \mathrm{cm}^{2}\right), \mathrm{M}=$ mass of the sensor disk $(\mathrm{gm}), \mathrm{Cp}=$ specific heat of the 
$\operatorname{disk}\left(\mathrm{cal} / \mathrm{gm}^{\circ} \mathrm{C}\right), \mathrm{A}=$ area of the disk $\left(\mathrm{cm}^{2}\right), \Delta \mathrm{T}=$ temperature rise of the disk $\left({ }^{\circ} \mathrm{C}\right)$, and $\Delta \mathrm{t}=$ exposure time (sec). Here, $\mathrm{M}$ can be further represented by Equation 2, where, $\mathrm{A}=$ area of the disk $\left(\mathrm{cm}^{2}\right), \mathrm{b}=$ thickness of the disk $(\mathrm{cm})$, and $\rho=$ density of the disk $\left(\mathrm{gm} / \mathrm{cm}^{3}\right)$. Eventually, Equation 1 can be rewritten as Equation 3, which was used to calculate heat flux in the sensor. According to Equation 3, it is clear that the $\rho$ and $\mathrm{Cp}$ are constant; consequently, $\mathrm{q}$ is directly dependent upon $\mathrm{b}$ and $\Delta \mathrm{T} / \Delta \mathrm{t}$. It seems that the accurate measurement of $\Delta \mathrm{T} / \Delta \mathrm{t}$ is essential to precisely calculate $\mathrm{q}$, and $\mathrm{b}$ is the most important affecting parameter to accurately measure $\Delta \mathrm{T} / \Delta \mathrm{t}$ or q. Thereafter, by using the heat flux (the average heat flux without any presence of tested fabric system was $\sim 0.45 \mathrm{cal} / \mathrm{s} / \mathrm{cm}^{2}$; and, this heat flux varied depending upon the tested fabric systems), the amount of thermal energy absorbed by the sensors was calculated in terms of $\mathrm{kJ} / \mathrm{m}^{2}$. And, the time required to generate a second-degree burn on each sensor (simulating skin) was predicted using the software programmed according to Henriques Burn Integral Equations (Equations 4 and 5). The time at which $\Omega$ reaches a value of 0.53 in Equation 5, it can be interpreted as the 'first-degree burn time'; and, when $\Omega$ reaches a value of 1 in Equation 5, it is called the 'second-degree burn time' [39, 40]. Considering the severity of the burns, this study mainly focused on the second-degree burn time. The average transmitted thermal energy and second-degree burn time of all the 10 sensors were reported as the thermal protective performance of the specimens. The average thermal protective performance of three specimens of a fabric system was considered as the thermal protective performance of the fabric system.

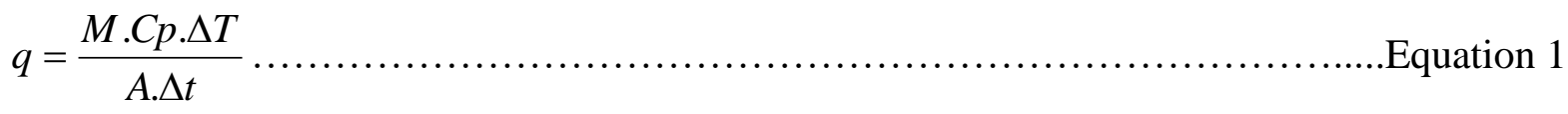

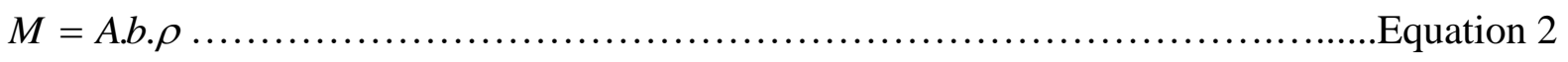

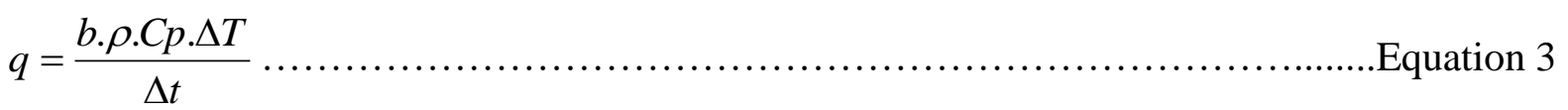


$\frac{d \Omega}{d t}=P \exp \left(\frac{-\Delta E}{R T}\right)$

Equation 4

Mathematical integration of Equation 4 yields,

$\Omega=\int_{0}^{t} P \exp ^{-(\Delta E / R T)} d t$ Equation 5

where,

$\Omega=$ burn injury parameter (dimensionless),

$\mathrm{P}=$ frequency factor $\left(2.185 \times 10^{124}\right.$ seconds $^{-1}$ at $\mathrm{T}<50^{\circ} \mathrm{C}$ and $1.823 \times 10^{51}$ seconds $^{-1}$ at $\mathrm{T}>$ $\left.50^{\circ} \mathrm{C}\right)$

$\Delta \mathrm{E}=$ activation energy $(\mathrm{J} / \mathrm{kmol})$,

$\mathrm{R}=$ universal gas constant $(8.315 \mathrm{~J} / \mathrm{kmolK})\left(\right.$ i.e., $\Delta \mathrm{E} / \mathrm{R}=93534.9 \mathrm{~K}$ at $\mathrm{T}<50^{\circ} \mathrm{C}$ and $\Delta \mathrm{E} / \mathrm{R}=$ $39109.8 \mathrm{~K}$ at $\mathrm{T}>50^{\circ} \mathrm{C}$ ),

$\mathrm{T}=$ temperature $(\mathrm{K})$ at epidermis skin depth of $75 \times 10^{-6} \mathrm{~m}$, and

$\mathrm{t}=$ time (seconds) for which $\mathrm{T}$ is above $317.15 \mathrm{~K}\left(44^{\circ} \mathrm{C}\right)$.

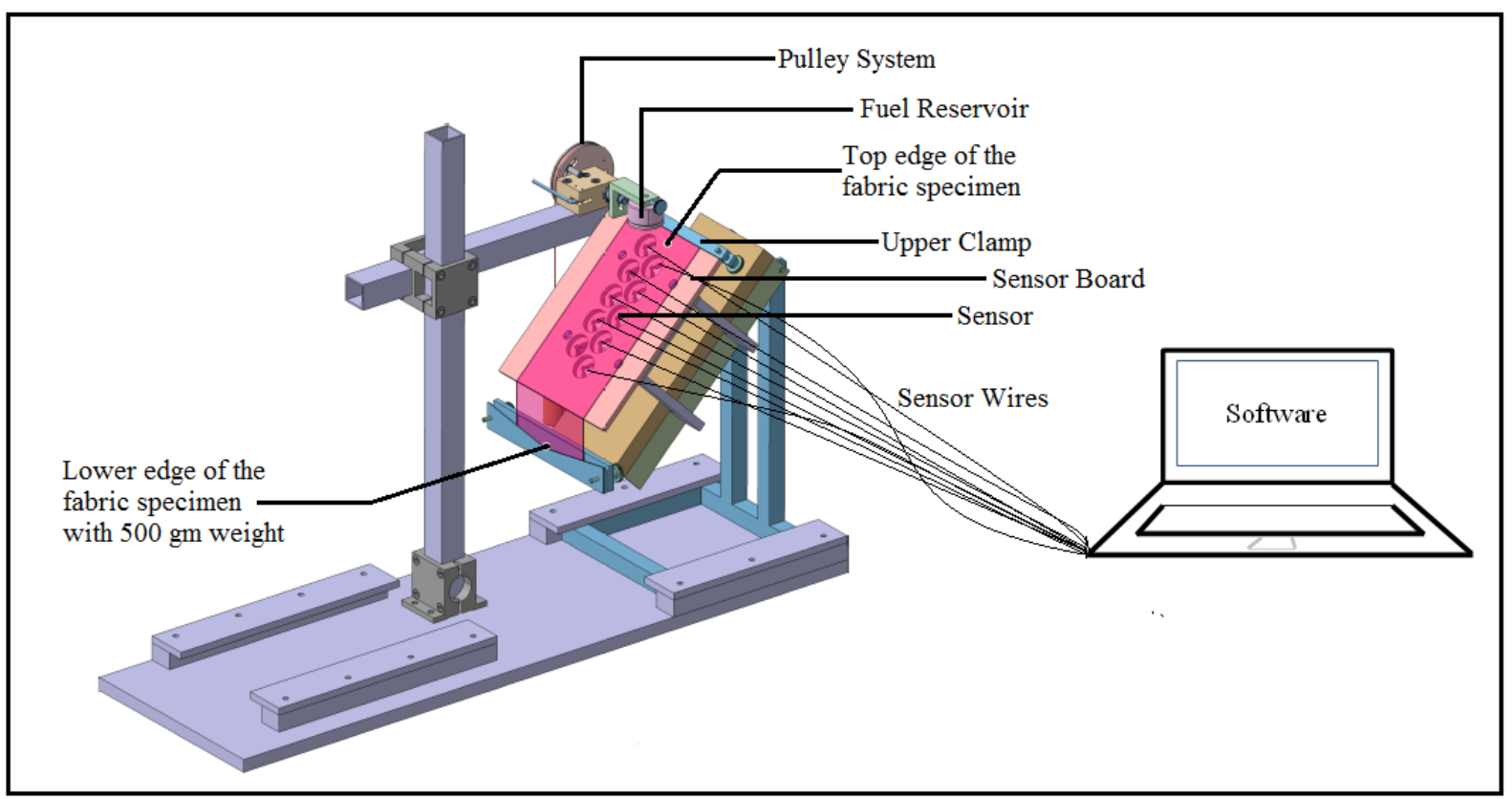

Figure 2: Schematic diagram of the Molotov cocktail exposure test

Procedure to analyze the experimental results

The transmitted thermal energy and second-degree burn times of the selected fabric 
systems (obtained from the test described above) were tabulated. According to this transmitted thermal energy and/or time required to generate a second-degree burn injury, the thermal protective performances of the fabric systems were ranked or rated. The physical properties (e.g., thickness, air permeability, thermal resistance, and evaporative resistance) and thermal protective performance (namely, transmitted thermal energy) of the fabric systems were normalized between -1 and +1 , with the average value set to zero. The normalized variable $\mathrm{X}_{\mathrm{i}, \text { norm }}$ was calculated by Equation 6 , where, $R_{i, \max }=\operatorname{Maximum}\left[\left(X_{i, \max }-\right.\right.$ $\left.\left.X_{i, \text { avg }}\right),\left(X_{i, \text { avg }}-X_{i, \text { min }}\right)\right]$. In Equation $6, X_{i}$ is the value of a selected variable (thickness, air permeability, thermal resistance, evaporative resistance, or second-degree burn time), $X_{i, \text { avg }}$ is the average value of that particular variable, $X_{i, \min }$ is the minimum value of that variable, $X_{i, \max }$ is the maximum value of that variable, and $R_{i, \max }$ is the maximum range between the average value and either the minimum or the maximum of that variable. This normalization process reduces the redundancy rates in the data by pulling out abnormal factors, and helps in distributing the data with normal probability plot.

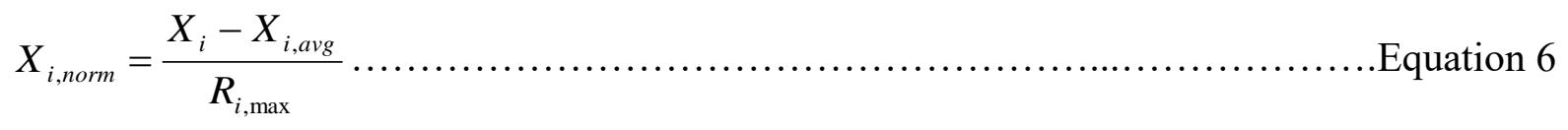

In order to understand the association between the physical properties of fabric systems and thermal protective performance (transmitted thermal energy), a linear regression ttest of the normalized data set was conducted using the SPSS Statistics 25 Data Editor (developed by IBM Corporation, USA). The + or - sign of the T-stat value obtained from the t-test was used to infer the association, and this association was justified through the predicted second-degree burn time or the theory of heat and mass transfer. P-values obtained from the t-test for individual fabric properties were analyzed to identify the fabric properties that significantly affected the thermal protective performance. Significance tests were carried out at the significance level 0.05 . Thus, any considered property with obtained P-value less than 0.05 was inferred to be statistically significant. The coefficients of determination $\left(\mathrm{R}^{2}\right)$ of the relation- 
ship plots between the significant fabric properties and the thermal protective performance were calculated. An $\mathrm{R}^{2}$ value with proximity to 1 was inferred as a strong association between the significant fabric property and thermal protective performance.

Further in this study, the standard Multiple Linear Regression (MLR) and Artificial Neural Network (ANN) models were used to predict the thermal protective performance using the significant properties obtained from the t-test analysis. This modeling was carried out using the SPSS Statistics 25 Data Editor (developed by IBM Corporation, USA) and MATLAB R2019a (developed by Mathworks, USA). To identify the best-fit high-performance models to predict the thermal protective performance, these MLR and ANN models were statistically compared based on their predicting performance parameters i.e., $\mathrm{R}^{2}$, Root Mean Square Error (RMSE), P-values. During the comparison, a model with high $\mathrm{R}^{2}$ (admired range: $>0.7$ ), low RMSE (admired range: <100) and P-values of <0.05 was inferred as the best-fit highperformance model.

\section{MLR Modeling}

A generic form of the MLR model is shown in Equation 7, where, $\mathrm{C}=$ identically distributed constant normal error, $(\mathrm{SFP})_{1} \ldots .(\mathrm{SFP})_{\mathrm{n}}=\mathrm{n}$ numbers of significant fabric properties (SFP), and $\beta_{1} \ldots \beta_{\mathrm{n}}=$ regression coefficients that determine relative strength of the respective SFP. An inherent limitation of the MLR model is that it should not be used to predict the output variable (thermal protective performance) beyond the range of the values of the input variables (SFP) employed in the model [41, 42].

Performance $=C+\beta_{1} \times(S F P)_{1}+\beta_{2} \times(S F P)_{2}+\ldots+\beta_{n} \times(S F P)_{n} \ldots \ldots \ldots \ldots \ldots$. Equation 7

\section{ANN Modeling}

ANN modeling is considered a powerful data modeling tool to capture and represent any kind of relationship between the input (significant fabric properties obtained from the ttests) and output (protective performance) variables [41-48]. It is a more efficient and suitable 
method in comparison with standard modeling methods for function approximation in the definite intervals of training data.

Different ANN models were developed in this study for predicting the protective performance of fabrics under Molotov cocktail exposure. In these ANN models, three layers were used - input layer, hidden layer, and output layer. These models were constructed using the MATLAB R2019a software [49]. An important consideration to construct a suitable model is to decide upon the architecture of the ANN. Multi-Layer Perceptron (MLP) architecture was employed in this study as MLPs are universal function approximators and are commonly used in developing ANN empirical models. Next, after setting different values for hyper-parameters (e.g., number of hidden layers and neurons, choice of activation functions) and different training algorithms (e.g., the gradient descent with momentum constant, Levenberg-Marquardt), a three-layered (input layer, one hidden layer, and output layer) feedforward backpropagation (the gradient descent with momentum constant backpropagation method was used in this study) ANN model was employed [47, 48]. The MATLAB generated schematic diagram of three-layered feed-forward backpropagation ANN model with four input fabric properties and three hidden neurons is shown in Figure 3.

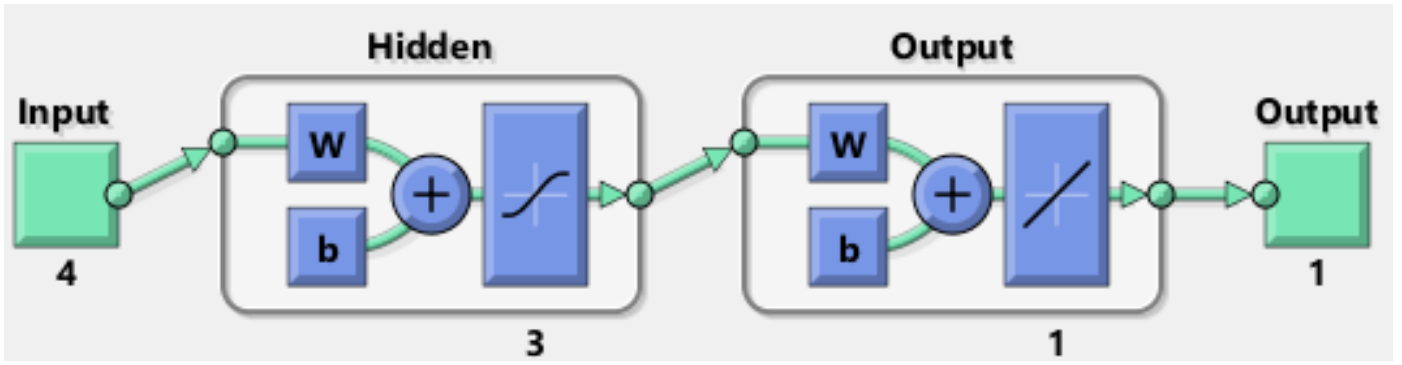

Figure 3. Schematic diagram of three-layered feed-forward backpropagation ANN model with four input and three hidden and one output neurons

The three-layered feed-forward model (Figure 3) was composed of connecting each layer of the neural network to the next layer (e.g., from the input to the hidden layer), but there were no connections back. The connections between the neurons in the particular layers determine the network function. The neural netwrok can be trained by adjusting the values of 
connections (weights) between neurons to perform a particular function. As the models used backpropagation supervised training form (the gradient descent with momentum constant), the final outputs predicted were always compared with the actual output, until the netwrok outut matches the actual output. Through this comparison, the backpropagation training algorithm calculated the prediction error and adjusted the values of the weights of various layers backward from the output to the input layer. This weight adjustment process worked based on a delta rule and decreased the error signal iteratively. The delta rule used is shown in Equation 8, where, $W(n)=$ the weight connecting between two neurons at the $\mathrm{n}^{\text {th }}$ iteration, $\Delta W(n)=$ the weight correction applied to the $W(n)$ at the $\mathrm{n}^{\text {th }}$ iteration, $E=$ predicted error signal at the $\mathrm{n}^{\text {th }}$ iteration, and $\eta=$ learning rate parameter constant. The hyperbolic tangent sigmoid transfer function (Equation 9) was assigned as an activation function in the hidden layer, and the linear function (Equation 10) was used in the output layer. These transfer functions can easily be applied with all types of data and can provide the best performance for an ANN model [41]. In the Equations 9 and 10, $x$ is the weighted sum of inputs to a neuron and $f(x)$ is the transformed output from that neuron. A challenge in using the feed-forward backpropagation ANN model was to decide the number of neurons in the hidden layer. Because a model trained with too few neurons in the hidden layer can not differentiate between complex patterns, and it might lead to a linear estimate of the actual relationship between the input and output variables; whereas, if the model is trained with too many neurons, the model follows a noise in the data set, and it might predict an inaccurate output [43]. Therefore, we trained the feedforward ANN models with two to ten hidden neurons, and the best predictive ANN models was found with three hidden neurons (Figure 3) [20, 50]. In the present study, MATLAB software randomly used $60 \%$ of the data (significant properties and transmitted energy) for the training, $20 \%$ of the data for the validation, and the remaining $20 \%$ of the data to test the predicting performance of the ANN models. To improve the generalization and prevent overfit of the ANN models, early stopping condition was used (i.e., the training continued 
until the validation error failed to decrease for six iterations or epochs). Contextually, it is notable that these ANN models were trained with a small dataset. As a consequence, these models could be unstable and may not be generalized for use in predicting protective performance of all types of fabrics.

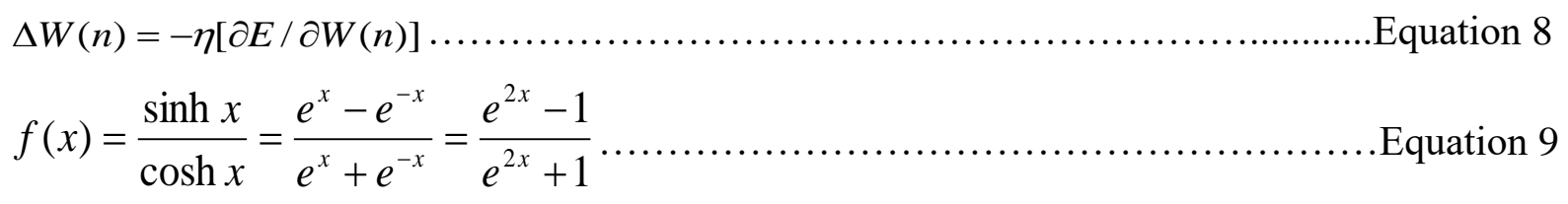
$f(x)=x$ Equation 10

\section{Summary of this Research Methodology Section with a Flow Chart}

In the previous sections, the methods used in this research were explained. In this section, these methods have been summarized in a flow chart.

Thermal Protective Fabric Selection

Fabric Physical Properties (Mass, Thickness, Air Permeability, Thermal Resistance, Evaporative Resistance) Evaluation

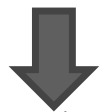

Thermal Protective Performance (Transmitted Thermal Energy through Fabrics, Seconddegree Burn Time Generated by Fabrics) Evaluation of the Fabrics

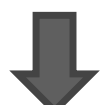

Characterization of the Thermal Protective Performance of Fabrics to Identify Significant Properties Affecting the Performance

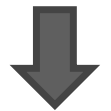

Modeling of the Thermal Protective Performance of Fabrics by Employing the Significant Fabric Properties

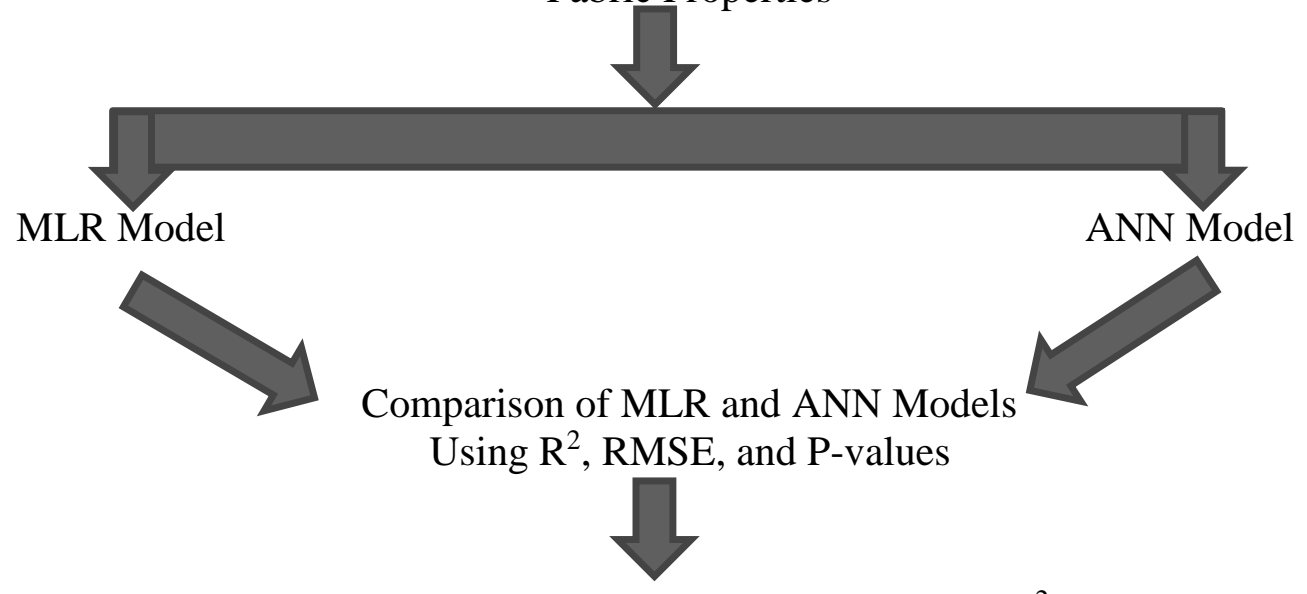

Identifying Best-Fit High-Performance Model with High R $^{2}$ and Low RMSE 


\section{Results and Discussion}

The thermal protective performances of the selected fabric systems in terms of transmitted thermal energy and second-degree burn time are presented in Table 3. Based on Table 3 , it is clear that the second-degree burn time generally decreases as the transmitted thermal energy increases. However, no second-degree burn has been observed if the transmitted thermal energy becomes less than $\sim 180 \mathrm{~kJ} / \mathrm{m}^{2}$. Notably, the transmitted thermal energy of triplelayered fabric systems is comparatively lower than the single- and double-layered fabric systems. Eventually, no second-degree burn has been usually observed in the case of triplelayered fabric systems. As triple-layered fabric systems are thicker than the single- and double-layered fabric systems, the chances of burns are relatively lower. As no burns occurred in the 4 fabric systems (Table 3), this study will mainly consider the transmitted thermal energy for statistically characterizing and empirically modeling the thermal protective performance.

Table 3: Thermal protective performance of the selected fabric systems

\begin{tabular}{|c|c|c|c|}
\hline \multirow{2}{*}{$\begin{array}{c}\text { Fabric } \\
\text { construction }\end{array}$} & \multirow[b]{2}{*}{ Fabric Systems } & \multicolumn{2}{|c|}{ Thermal Protective Performance } \\
\hline & & $\begin{array}{l}\text { Transmitted Thermal Energy } \\
\qquad\left(\mathrm{kJ} / \mathrm{m}^{2}\right)\end{array}$ & $\begin{array}{l}\text { Second-degree Burn } \\
\text { Time (seconds) }\end{array}$ \\
\hline Single-layered & $\mathrm{A}$ & 475.86 & 25.35 \\
\hline \multirow{4}{*}{ Double-layered } & $\mathrm{AB}$ & 208.29 & 74.0 \\
\hline & $\mathrm{AD}$ & 154.09 & No Burn \\
\hline & $\mathrm{AE}$ & 306.98 & 49.61 \\
\hline & EA & 187.67 & 46.50 \\
\hline \multirow{4}{*}{ Triple-layered } & AEB & 188.63 & 84.50 \\
\hline & $\mathrm{AEC}$ & 179.76 & No Burn \\
\hline & AED & 131.83 & No Burn \\
\hline & EAC & 113.22 & No Burn \\
\hline
\end{tabular}

\section{Characterization of the thermal protective performance of fabrics}

In general, convection is the primary mode of heat transfer in the Molotov cocktail exposure. In this exposure, flammable liquid enters through the pores of the fabrics. This movement of the liquid carries the flame within the fabrics, transfers the convective thermal energy through the fabrics, and generates burns on the wearers' skin. Results obtained from 
the t-tests (T-stat and P-value) to analyze the association between fabric system properties and transmitted thermal energy are presented in Table 4.

Table 4. Results of t-tests between fabric system properties and transmitted thermal energy in Molotov cocktail exposure

\begin{tabular}{|c|c|c|}
\hline Fabric System Properties & \multicolumn{2}{|c|}{ Transmitted Thermal Energy } \\
\cline { 2 - 3 } & T-Stat & P-value \\
\hline Thickness & -3.813 & 0.007 \\
\hline Air permeability & 1.497 & 0.178 \\
\hline Thermal resistance & -3.518 & 0.010 \\
\hline Evaporative resistance & -2.464 & 0.043 \\
\hline
\end{tabular}

According to Table 4, T-stat values for thickness, thermal resistance, and evaporative resistance are negative. It indicates a negative relationship between these properties and transmitted thermal energy. As the fabric systems with high thickness, high thermal resistance, and high evaporative resistance could trap more dead air in comparison to the fabrics with low thickness, low thermal resistance, and low evaporative resistance. This trapped dead air could enhance the thermal insulation of the fabric systems and lower the transmission of the thermal energy $[22,24,51,52]$. Due to the lower transmitted thermal energy, the fabric systems with high thickness, high thermal resistance, and high evaporative resistance take longer time to generate second-degree burns on wearers' bodies under the Molotov cocktail exposure. Furthermore, according to Table 4, the T-Stat value of air permeability is positive. It means a positive relationship exists between the air permeability and transmitted thermal energy. This is because a fabric system with high air permeability possesses high porosity $[8,53]$. Due to this high porosity, the flammable liquids may easily transmit through the fabric system to the wearers' skins. This situation ultimately carries the flame inside the fabric systems and transmits the thermal energy towards the wearers and generates burns on their skins.

Table 4 further shows that P-values associated with thickness and thermal resistance are significantly lower than 0.05 . It means both thickness and thermal resistance are the significant fabric properties that can affect the transmitted thermal energy. Contextually, it is notable that thermal resistance of a fabric system depends on its thickness (Thermal Resistance 
= Thickness/Thermal Conductivity); eventually both of these properties are mutually dependent $[8,22]$. As using the mutually dependent properties could disturb the efficiency of the models, this study will only consider thermal resistance as the most significant property for the transmitted thermal energy, in turn, second-degree burn time. Furthermore, it is evident from Figure 4, two fabric systems with the same thermal resistance could transfer different amounts of thermal energy through the fabric systems. For example, AE (or AEC) and EA (or EAC) fabric systems have same thermal resistance $0.095^{\circ} \mathrm{K} \cdot \mathrm{m}^{2} / \mathrm{W}$ (thermal resistance of AEC or EAC is $0.151{ }^{\circ} \mathrm{K} \cdot \mathrm{m}^{2} / \mathrm{W}$ ); however, the transmitted thermal energy through these fabric systems are very different. This phenomena could be explained based on the surface structure of the outer layer of these fabric systems and its fire behaviour during the Molotov cocktail exposure (Figure 5). The outer layer of AE fabric system, i.e., 'A', is a plain weave, rip-stop woven fabric. This woven fabric is constructed with the interlacement of warp and weft yarns making it a porous medium. Due to this porous structure, the flammable liquids move easily through fabric ' $A$ ' resulting in flame reaching more closer to the skin. On the other hand, the outer layer of EA fabric system, i.e., 'E', is a plain weave Nomex ${ }^{\circledR}$ fabric coated with polyurethane (PU) film. Due to the smooth PU coated surface structure, the EA fabric system restricted the transfer of flammable liquids through the system (notably, moisture barried E in EA fabric system could be damaged more in comparison to the outer layer $\mathrm{A}$ in $\mathrm{AE}$ fabric system due to the restriction of the flammable liquid tranfer, holding the liquid, and continious burning of PU coating); rather, it dispersed the liquids on the surface or driped the liquids through the edges of the system. Eventually, the transmitted thermal energy is higher for AE fabric system in comparison to the EA fabric system. It is also notable that transmitted thermal energy through the AD fabric system is the lowest among the doublelayered fabric systems; this is because the thermal resistance of the AD fabric system is the highest among the double-layered fabric systems. Although a fabric system with high thermal resistance could lower the transmission of the energy, it is not absolutely true for the triple- 
layered fabric systems. For example, the AED fabric system possesses the highest thermal resistance among the selected triple-layered fabric systems; however, the transmitted thermal energy is the lowest in case of the EAC fabric system. This is because the thickest AED fabric system considerably absorbs most of the flammable liquids, which changes the fire behavior and generates high flame (Figure 6). This situation ultimately transfers more thermal energy towards the wearers' skins. Additionally, the thickest AED fabric system could store more thermal energy in comparison to the EAC fabric system and this stored energy get transmitted to the wearers' skins over the time of 100 seconds test duration used in this study [54].

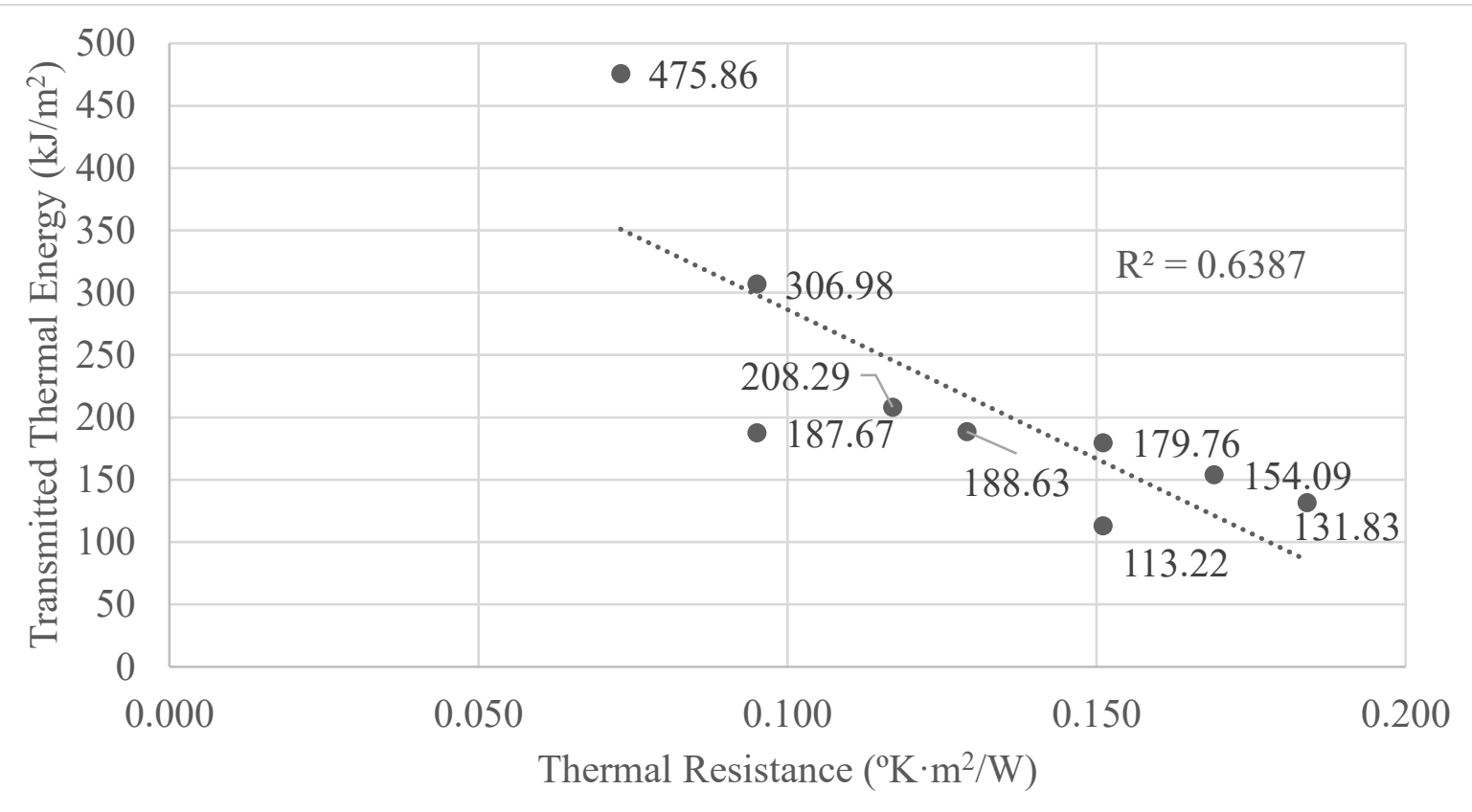

Figure 4: Relationship between the thermal resistance and transmitted thermal energy of the fabric systems 

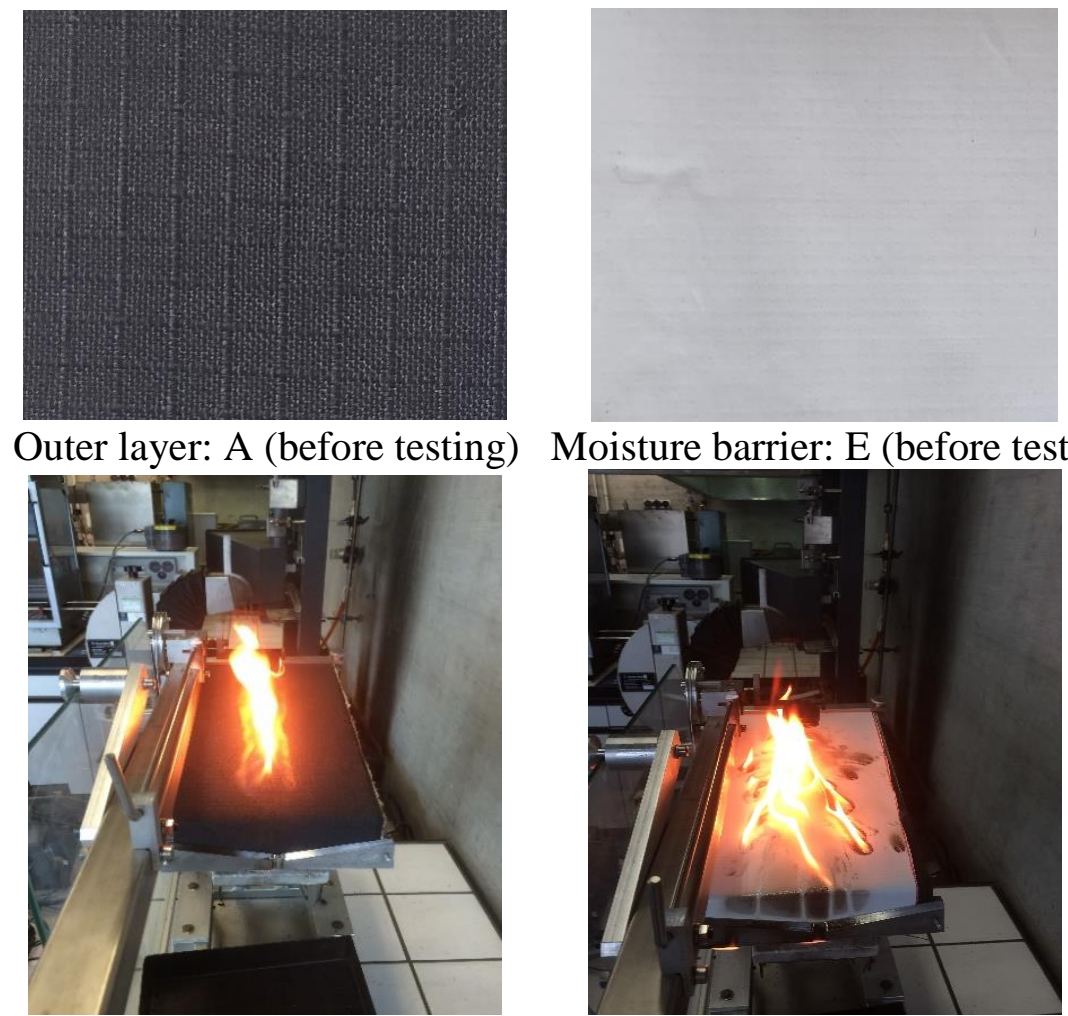

$\mathrm{AE}$

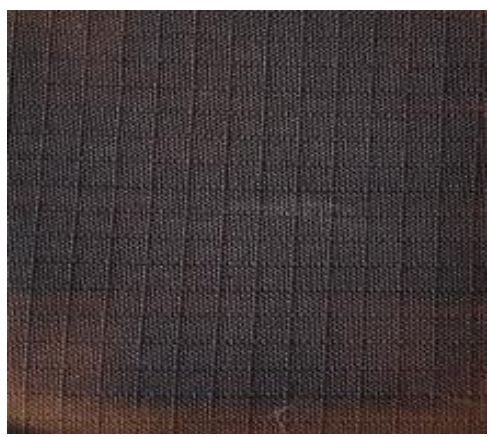

Most damaged area of the outer layer: A (after testing)
EA

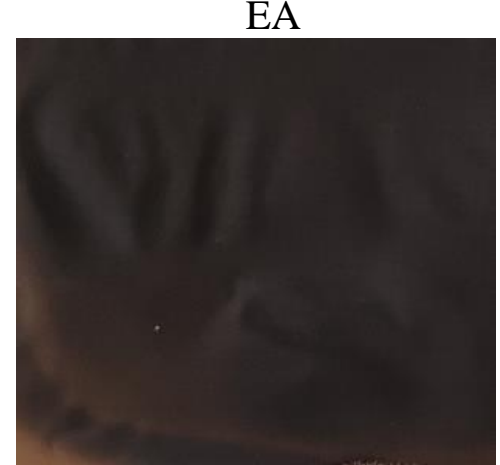

Most damaged area of the moisture barrier: $\mathrm{E}$ (after testing)

Figure 5: Outer surface structure and fire behavior of the AE and EA fabric systems

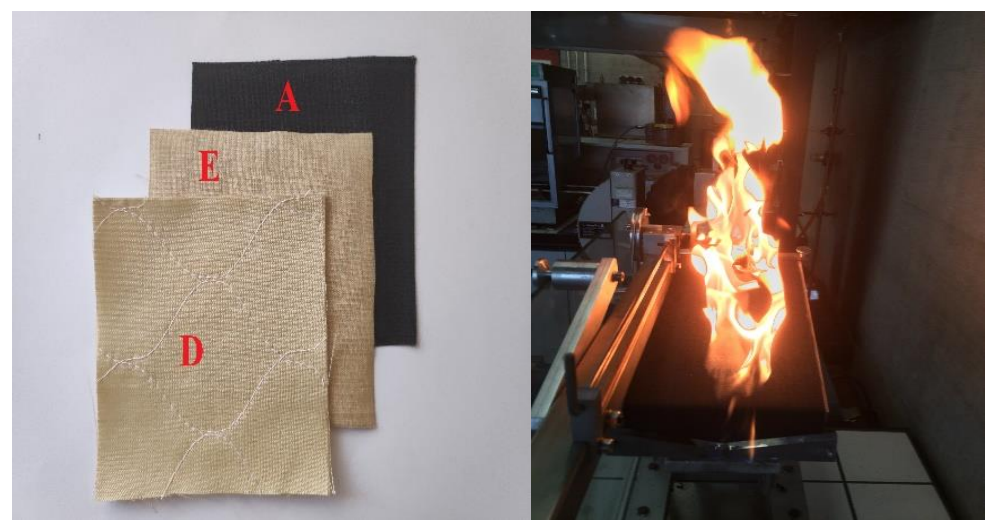

Figure 6: Surface structure (technical back surface structure of the layers is shown here; technical face surface structures is as shown in Figure 1) and fire behavior of the of the AED fabric system (after testing, the outer layer A damaged most among all the layers and it is similar to outer layer A in Figure 5) 
Furthermore, based on Table 4, it is evident that the P-value of evaporative resistance is lower than the 0.05 . It means evaporative resistance is also a significant property to affect the transmitted thermal energy. However, by comparing the $R^{2}$ values in Figures 4 and 7 , it is clear that the $R^{2}$ value of evaporative resistance is lower than the $R^{2}$ value of thermal resistance. Hence, evaporative resistance is less significant property in comparison to the thermal resistance for affecting the transmitted thermal energy. Actually, a fabric system could possess high evaporative resistance if it comprises a moisture barrier; however, this moisture barrier does not add much thermal insulation to the fabric system; eventually, a fabric system with high evaporative resistance may not provide high thermal insulation and that can lower its impact on the transmitted thermal energy.

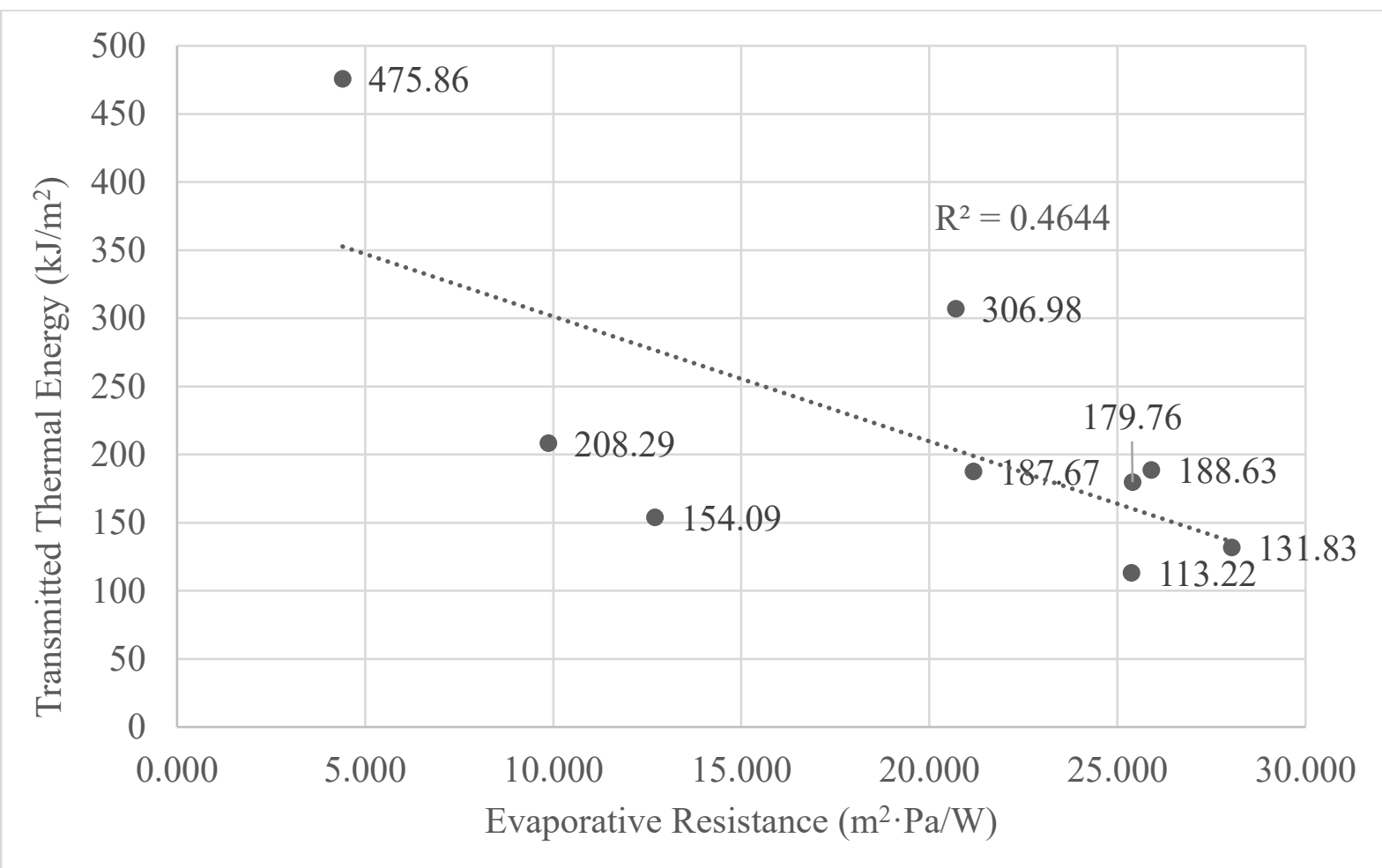

Figure 7: Relationship between the evaporative resistance and transmitted thermal energy of the fabric systems

\section{Modeling for predicting the thermal protective performance of fabrics}

Based on the above discussion, it can be inferred that thermal resistance and evaporative resistance are the two most significant properties to affect the transmitted thermal energy, in turn, thermal protective performance of the fabric systems. In the following section, these 
significant properties are employed in the MLR and ANN modeling techniques in order to develop models for predicting the thermal protective performance of the fabric systems in terms of transmitted thermal energy. Notably, the MLR and ANN models developed in the following section are based on the fabric systems used in this study. In future, the performance $\left(\mathrm{R}^{2}\right.$, RMSE) of these models could be improved by incorporating a greater number of fabric systems with a wide range of properties and performance.

\section{MLR model}

The MLR model for predicting the thermal protective performance of fabric systems under Molotov cocktail exposure is shown in Equation 11. In this model, the fabric properties that significantly affected the thermal protective performance of fabric systems were employed in the SPSS Statistics 25 Data Editor software according to the MLR modelling method described in the research methodology section.

Transmitted Energy $=545.002-1823.170 \times$ Thermal Resistance $-4.820 \times$ Evaporative Resistance Equation 11

\section{ANN model}

In order to predict the thermal protective performance by ANN models in terms of transmitted thermal energy, the ANN modelling method described in the research methodology section was followed. Here, the values of two significant fabric properties for the transmitted thermal energy were employed to code the computer program for ANN model using MATLAB software. This program was executed in the MATLAB software for predicting the transmitted thermal energy of the fabric systems. A schematic diagram (Figure 8) and code for the ANN model that was used to predict the transmitted thermal energy of the fabric systems under Molotov cocktail exposure is presented below: 


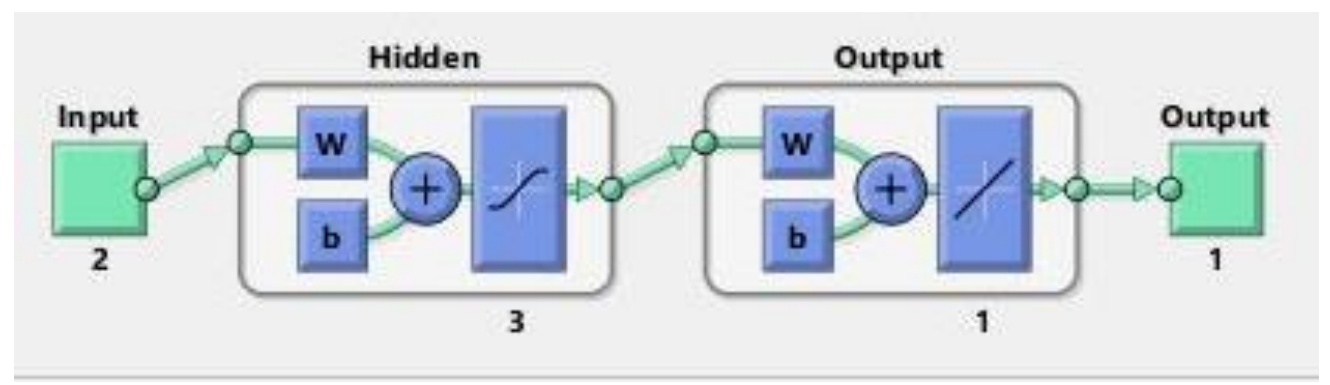

Figure 8. Schematic diagram of three-layered feed-forward backpropagation ANN model with two significant fabric properties and three hidden neurons

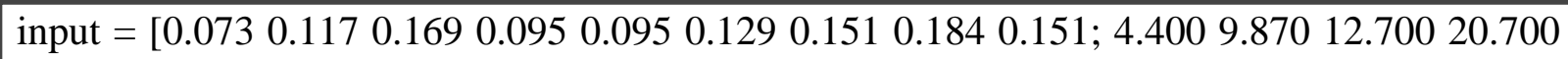
$21.17025 .90025 .40028 .03025 .370]$;

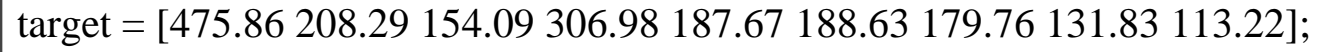

trainFcn = 'trainlm'; \% Levenberg-Marquardt backpropagation.

$\%$ creating a fitting network

hiddenLayerSize = 3;

netp1 = fitnet(hiddenLayerSize, trainFen);

$\%$ setting up the division of data for training, validation, testing

netp1.divideParam.trainRatio $=60 / 100$;

netp1.divideParam.valRatio $=20 / 100$;

netp1.divideParam.testRatio $=20 / 100$;

$\%$ training the network

[netp1,tr] = train(netp1,input,target);

$\%$ testing the network

$\mathrm{y}=$ netp1(input);

$\%$ assessing the performance of the trained network. The default performance function is mean squared error.

performance $=$ perform $($ netp 1, target, $\mathrm{y})$

$\%$ saving the trained network

save netp1;

$\%$ loading the trained network

load netp1;

$\%$ calculating the root mean square error

rmse $=$ sqrt(performance);

$\%$ viewing the network

view(netp1);

$\%$ using the regression analysis to judge the network performance

$[\mathrm{m}, \mathrm{b}, \mathrm{r}]=\operatorname{postreg}(\mathrm{y}, \operatorname{target})$;

plotregression(target,y,'Regression');

$\%$ plotperform(tr);

\section{Comparison between MLR and ANN models}

In this section, the MLR and ANN models obtained for predicting the thermal protective performance of the fabric systems under Molotov cocktail exposure are statistically compared according to the method described in the research methodology section. The predicting 
performance parameters ( $\mathrm{R}^{2}$, RMSE, P-values) of these MLR and ANN models are presented in Table 5.

Table 5. The $\mathrm{R}^{2}$, RMSE, and P-values of the MLR and ANN models

\begin{tabular}{|c|c|c|c|}
\hline \multirow{2}{*}{ Model Types } & \multicolumn{3}{|c|}{ Model Performance Parameters } \\
\cline { 2 - 3 } & $\mathrm{R}^{2}$ & RMSE & P-values \\
\hline MLR & 0.73 & 191.38 & \multirow{2}{*}{0.02} \\
\hline ANN & 0.94 & 37.42 & \\
\hline
\end{tabular}

Table 5 presents that the prediction models are valid as the P-values are less than 0.05 . In a comparison between the MLR and ANN models, it can be identified that the $\mathrm{R}^{2}$ value of MLR model is lower than the ANN model; hence, the predictability of the ANN model works better than the MLR model. Moreover, the prediction error (RMSE) by the ANN model is much lower than the MLR model. The best validation performance of this ANN model was found at epoch 2 and there was a strong relationship between the targetted value (i.e., the actual value of the transmitted thermal energy obtained from the experiment) and ANN model obtained output value (Figure 9). In summary, the ANN model performed better than the MLR model in terms of the precision and accuracy for predicting the thermal protective performance under Molotov cocktail exposure. Thus, it is worthwhile to use the best-fit ANN model for predicting the thermal protective performance of the fabric systems under Molotov cocktail exposure.
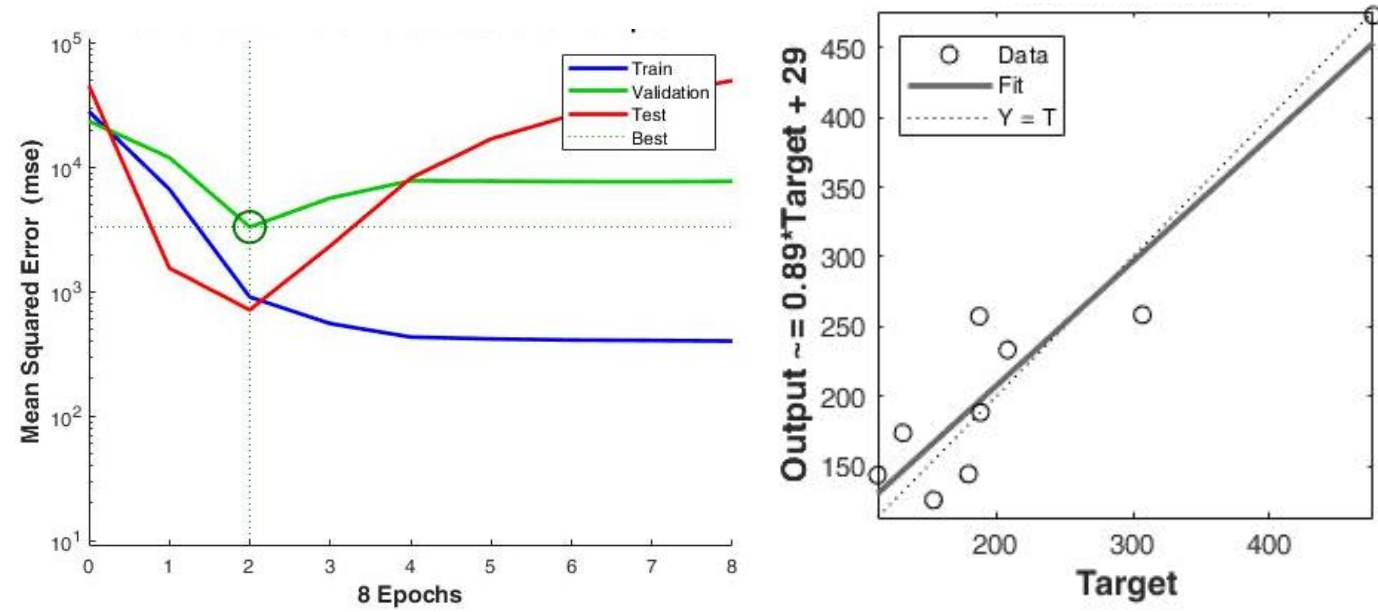

Figure 9: Performance and regression plots of the developed ANN model 


\section{Summary and Conclusion}

High-risk sectors' employees are often exposed to fires while on-duty. In this fire exposure, the workwear used by these employees mainly provide them protection. Considering this, many researchers characterized and modeled the thermal protective performance of the fabrics used in the workwear under different types of fire exposures such as flame, radiantheat, and hot surface contact. However, no studies have been carried out to characterize and model the thermal protective performance of fabrics under an important fire exposure - i.e., Molotov cocktail exposure.

Based on this study, it can be concluded that a workwear made up of a fabric with high thickness, high thermal resistance, and high evaporative resistance could provide better protection to high-risk sectors' employees. However, if the fabric is highly air permeable, the workwear cannot provide proper protection to the employees. Notably, thermal resistance and evaporative resistance are the most significant properties that can affect the thermal protective performance of the fabrics used in the workwear under Molotov cocktail exposure. This study further employed these significant properties for developing the models that can conveniently predict the thermal protective performance of the fabrics under Molotov cocktail exposure. In this study, it has been found that state-of-the-art ANN model could accurately predict the performance in comparison to the MLR model.

In future, the developed models can be used by industry and academic researchers for predicting the thermal protective performance of fabrics under Molotov cocktail exposure. The understanding developed through this study could also lead textile and materials scientists to develop a novel fabric-based workwear that can provide better occupational health and safety to the high-risk sectors' employees. 


\section{Future Work}

Considering the limited resources and time, this study primarily focused on the thermal protective performance of fabrics. However, this fabrics-based workwear should also provide protection from bullet and stab; therefore, in future, a study on impact and penetration resistance of these fabrics could be conducted. Additionally, these fabrics may have an impact on comfort of the wearers; therefore, a study could also be conducted to evaluate the thermophysiological, fit, and tactile comfort performance of these fabrics.

\section{Acknowledgement}

The authors like to thank Leonie El Issawi-Frischknecht at Empa, Switzerland for her support during the testing.

\section{Funding}

Sumit Mandal would like to thank Oklahoma State University, USA for providing him a Start-up Research Grant. Sumit Mandal would also like to thank University of Alberta, Canada for providing him with the Edmonton Consular Ball Scholarship during his $\mathrm{PhD}$ to visit and conduct this research at Empa, Swiss Federal Laboratories for Materials Science and Technology, Switzerland.

\section{References}

1. Rossi, R. (2003). Firefighting and its influence on the body. Ergonomics, 46(10), 10171033.

2. Shalev, I., \& Barker, R. L. (1984). Protective fabrics: a comparison of laboratory methods for evaluating thermal protective performance in convective/radiant exposures. Textile Research Journal, 54(10), 648-654.

3. Song G. (2004). Modeling thermal protection outfit for fire exposures. PhD Thesis. North Carolina State University, Raleigh, USA. 
4. Kahn, S. A., Patel, J. H., Lentz, C. W., \& Bell, D. E. (2012). Firefighter burn injuries: predictable patterns influenced by turnout gear. Journal of Burn Care \& Research, 33(1), 152156.

5. Rossi, R. M., \& Bolli, W. P. (2008). Assessment of radiant heat protection of firefighters' jackets with a manikin. In C. Nelson and N. Henry (Eds.), Performance of Protective Clothing: Issues and Priorities for the $21^{\text {st }}$ Century: Seventh Volume, ASTM STP 14447S (pp. 212-223). USA: American Society for Testing and Materials.

6. Mandal, S., \& Song, G. (2011, May). Characterization of protective textile materials for various thermal hazards. Fiber Society Spring Conference, Kowloon, Hong Kong.

7. Rossi, R., \& Zimmerli, T. (1994, January). Influence of humidity on the radiant, convective and contact heat transmission through protective clothing materials. Fifth International Symposium on Performance of Protective Clothing: Improvement through Innovation, San Francisco, USA.

8. Song, G., Mandal, S., \& Rossi, R. (2016). Thermal protective clothing: a critical review. United Kingdom: Woodhead Publishing.

9. Song, G., Paskaluk, S., Sati, R., Crown, E. M., Dale, J. D., \& Ackerman, M. (2011). Thermal protective performance of protective clothing used for low radiant heat protection. Textile Research Journal, 81(3), 311-323.

10. Emam, H. E. (2019). Generic strategies for functionalization of cellulosic textiles with metal salt. Cellulose, 26, 1431-1447.

11. Emam, H. E., Darwesh, O. M., Abdelhameed, R. M. (2020). Protective cotton textiles via amalgamation of cross-linked imidazole frameworks. Industrial and Engineering Chemistry Research, 59(23), 10931-10944.

12. Hasse, J. (2013). Flame resistant clothing standards and regulations. In F. S. Kilinc (Ed.), Handbook of Fire Resistant Textiles (pp. 364-414). England: Woodhead Publishing. 
13. Mandal, S. (2016). Studies of the thermal protective performance of textile fabrics used in firefighters' clothing under various thermal exposures. PhD Thesis, University of Alberta, Edmonton, Canada.

14. International Organization for Standardization. (2016). ISO 9151: protective clothing against heat and flame - determination of heat transmission on exposure to flame. Geneva, Switzerland.

15. International Organization for Standardization. (2002). ISO 2002: protective clothing protection against heat and fire - method of test: evaluation of materials and material assemblies when exposed to a source of radiant heat. Geneva, Switzerland.

16. ASTM International. (2019). ASTM F 2700: standard test method for unsteady-state heat transfer evaluation of flame resistant materials for clothing with continuous heating. Annual Book of ASTM Standards (Vol. 11.03, 12 pp.). West Conshohocken, PA, USA.

17. ASTM International. (2018). ASTM F 1060: standard test method for evaluation of conductive and compressive heat resistance (CCHR). Annual Book of ASTM Standards (Vol. 11.03, 7 pp.). West Conshohocken, PA, USA.

18. ASTM International. (2013). ASTM F 2703: Standard Test Method for Unsteady-State Heat Transfer Evaluation of Flame Resistant Materials for Clothing with Burn Injury Prediction. Annual Book of ASTM Standards (Vol. 11.03, 16 pp.). West Conshohocken, PA, USA.

19. Rossi, R., Bolli, W., \& Stämpfli, R. (2008). Performance of firefighters' protective clothing after heat exposure. International Journal of Occupational Safety and Ergonomics, 14(1), 55-60.

20. Mandal, S., \& Song, G. (2014). An empirical analysis of thermal protective performance of fabrics used in protective clothing. The Annals of Occupational Hygiene, 58(8), $1065-$ 1077. 
21. Mandal, S., \& Song, G. (2016). Characterizing thermal protective fabrics of firefighters' clothing in hot surface contact. Journal of Industrial Textiles. DOI: $10.1177 / 0123456789123456$.

22. Mandal, S., Song, G., Ackerman, M., Paskaluk, S., \& Gholamreza, F. (2013). Characterization of textile fabrics under various thermal exposures. Textile Research Journal, 83(10), 1005-1019.

23. Mandal, S., Annaheim, S., Greve, J., Camenzind, M., \& Rossi, M. R. (2019). Modeling for predicting the thermal protective and thermo-physiological comfort performances of fabrics used in firefighters' clothing. Textile Research Journal, 89(14), 2836-2849.

24. Mandal, S., Camenzind, M., Annaheim, S., \& Rossi, M. R. (2019). Characterization and modelling of thermal protective performance of fabrics under radiant-heat exposure. Journal of Industrial Textiles, 48(7), 1184-1205.

25. https://www.policeone.com/george-floyd-protest/articles/at-least-50-secret-service-agentsinjured-by-rioters-T1teVnFiVbfZa9zI/

26. https://www.theyeshivaworld.com/news/featured/1866267/50-secret-service-agentsinjured-outside-white-house-molotov-cocktails-thrown.html

27. Kemp, S. E., Annaheim, S., Rossi, R., \& Camenzind, M. (2016). Test method for characterising the thermal protective performance of fabrics exposed to flammable liquid fires. Fire and Materials, 41(6), 750-767.

28. Makinen, H. (2008). Firefighters protective clothing. In R. A. Scott (Ed.), Textiles for Protection (pp. 622-647). England: Woodhead Publishing.

29. Guan, M., Psikuta, A., Camenzind, M., Li, J., Mandal, S., Rossi, M. R., \& Annaheim, S. (2019). Effect of perspired moisture and material properties on evaporative cooling and thermal protection of the clothed human body exposed to radiant heat. Textile Research Journal, 89(18), 3663-3676. 
30. Guan, M., Annaheim, S., Camenzind, M., Li, J., Mandal, S., Psikuta, A., \& Rossi, M. R. (2019). Moisture transfer of the clothing-human body system during continuous sweating under radiant heat. Textile Research Journal, 89(21-22), 4537-4553.

31. Andersson, C. J. (1999). Relationship between physical textile properties and human comfort during wear trials of chemical biological protective garment systems. MSc Thesis, University of Alberta, Edmonton, Canada.

32. Wen, S. (2014). Physiological strain and physical burden in chemical protective coveralls. PhD Thesis, University of Alberta, Edmonton, Canada.

33. ASTM International. (2009). ASTM D 3776: Standard test method for mass per unit area (weight) of fabric. Annual Book of ASTM Standards (Vol. 7.01, 5 pp.). West Conshohocken, PA, USA.

34. ASTM International. (1996). ASTM D 1777: Standard test method for thickness of textile material. Annual Book of ASTM Standards (Vol. 7.01, 5 pp.). West Conshohocken, PA, USA.

35. ASTM International. (2004). ASTM D 737: Standard test method for air permeability of textile fabrics. Annual Book of ASTM Standards (Vol. 7.01, 5 pp.). West Conshohocken, PA, USA.

36. ASTM International. (2014). ASTM D 1518: Standard test method for thermal resistance of batting systems using a hot plate. Annual Book of ASTM Standards (Vol. 7.01, 6 pp.). West Conshohocken, PA, USA.

37. ISO. (2014). ISO 11092: Textiles - physiological effects - measurement of thermal and water-vapor resistance under steady-state conditions (sweating guarded-hotplate test). ISO (15pp.). Geneva, Switzerland.

38. ISO. (2005). ISO 139: Textiles - standard atmospheres for conditioning and testing. ISO (6pp.). Geneva, Switzerland. 
39. Henriques, F. C. (1947). Studies of thermal injury; the predictability and the significance of thermally induced rate processes leading to irreversible epidermal injury. Archives of Pathology, 43(5) 489-502.

40. Heath, D. W. (2000). A liquid cooled heat flux transducer for use in evaluating the thermal protective performance of firefighters' clothing. MSc Thesis. North Carolina State University, Raleigh, USA.

41. Hui, C. L., \& Ng, S. F. (2009). Predicting seam performance of commercial woven fabrics using multiple logarithm regression and artificial neural networks. Textile Research Journal, 79(18), 1649-1657.

42. Majumdar, P. K., \& Majumdar, A. (2004). Predicting the breaking elongation of ring spun cotton yarns using mathematical, statistical and artificial neural networks models. Textile Research Journal, 74(7), 652-655.

43. Murrells, C. M., Tao, X. M., Xu, B. G., \& Cheng, K. P. S. (2009). An artificial neural network model for the prediction of spirality of fully relaxed single jersey fabrics. Textile Research Journal, 79(3), 227-234.

44. Pynckels, F., Kiekens, P., Sette, S., Van-Langenhove, L., \& Impe, K. (1995). Use of neural nets for determining the spinnability of fibres. Journal of Textile Institute, 86(3), 425437.

45. Arupjoyti, S., \& Iragavarapu, S. (1998). New electrotopological descriptor for prediction of boiling points of alkanes and aliphatic alcohols through artificial neural network and multiple linear regression analysis. Computers and Chemistry, 22(6), 512-522.

46. Zaefizadeh, M., Khayatnezhad, M., \& Gholamin, R. (2011). Comparison of multiple linear regression (MLR) and artificial neural networks (ANN) in predicting the yield using its components in hulless barley. Journal of Agricultural and Environmental Science, 10(1), 60-64. 
47. Ozkan, I., Kuvvetli, Y., Baykal, P. D., \& Sahin, C. (2015). Predicting the intermingled yarn number of nips and nips stability with neural network models. Indian Journal of Fibre and Textile Research, 40(3), 267-272.

48. Ozkan, I., Kuvvetli, Y., Baykal, P. D., \& Erol, R. (2014). Comparison of the neural network model and linear regression model for predicting the intermingled yarn breaking strength and elongation. The Journal of Textile Institute, 105(11), 1203-1211.

49. https://www.mathworks.com/company/newsroom/mathworks-announces-release-2019aof-matlab-and-simulink.html.

50. Mandal, S., \& Song, G. (2012, August). Modeling of thermal protective performance of commercial woven fabric using artificial neural network. $9^{\text {th }}$ International Meeting for Manikins and Modeling, Tokyo, Japan.

51. Mandal, S., Annaheim, S., Camenzind, M., \& Rossi, M. R. Radiant-heat protective performance of fabrics used in firefighters' clothing: a scientific study. Fiber Society Spring Conference, Aachen, Germany, May 17-19, 2017.

52. Mandal, S., Annaheim, S., Camenzind, M., \& Rossi, M. R. Characterizing thermal protective and thermo-physiological comfort performance of fabrics used in firefighters' clothing - using 2D intermediate tests. Fiber Society Fall Conference, California, USA, October 29-31, 2018.

53. Mandal, S., Annaheim, S., Capt, A., Greve, J., Camenzind, M., \& Rossi, M. R. (2019). A categorization tool for fabric systems used in firefighters' clothing based on their thermal protective and thermo-physiological comfort performances. Textile Research Journal, 89(16), 3244-3259.

54. Song, G., Cao, W., \& Gholamreza, F. (2011). Analyzing stored thermal energy and thermal protective performance of clothing. Textile Research Journal, 81(11), 1124-1138. 